\title{
Spinal arthroplasty is here to stay: editorial
}

\author{
Bernhard Meyer
}

Received: 18 September 2009 / Accepted: 22 September 2009/Published online: 21 October 2009

(C) Springer-Verlag 2009

The authors of this review [1] are to be commended for the diligence they displayed in compiling an overview on the existing literature regarding spinal arthroplasty. Especially helpful and on the positive side are the tables summarising the results of current randomised controlled trials (RCTs), which is very informative for the readers.

The information in this review serves the purpose to provide that part of our neurosurgical community, which is not intensively familiar with this topic (especially lumbar total disc replacement (TDR)) with a modern, condensed, and balanced view on it, plus an outlook that will most probably happen with this technology.

As such, this review should provide additional and new information if compared with earlier reviews on this topic (i.e. [2, 3]). In this regard, the literature search is incomplete, as the authors state themselves. The reason for this is not quite obvious for me, because it is not very inspiring to just reiterate known facts and uncertainties.

While I agree with many things, I am also happy to supplement some additional information I feel necessary plus a somewhat different interpretation of several related issues. I hope the authors, who had a tremendous task, will consider this as normal within the process of peer review, because I am to express opposing views on a number of facts. There is no absolute truth for most things in medicine as there would be in a simple black and white world; there are merely different shades of grey, with my "grey" having a different hue. It will be up to the individual reader to decide.

\section{B. Meyer $(\bowtie)$}

Department of Neurosurgery, Technical University of Munich, Klinikum rechts der Isar,

Ismaninger Str. 22,

81675 Munich, Germany

e-mail: Bernhard.meyer@1rz.tum.de
My first problem is a certain lack of focus on the actual topic, i.e. total disc replacement, which is absolutely necessary because of the sheer amount of information on disc protheses alone, especially if one likes to cover lumbar and cervical together. The authors go astray and comment "en passant" on related nonfusion technologies (by the way, most people will consider this expression as the generic term for these technologies).

As such, they comment on interspinous devices (IPDs) and nucleus replacement. While they state that the former "has been abandoned due to bad results", they reserve a lot of space with a more positive tone for the latter. However, reality is in sharp contrast to that, and the literature clearly gives a completely different picture. So this statement is founded on nothing but personal preference and gut feeling.

Whether one likes it or not, IPDs are in widespread and unfortunately uncontrolled use in many countries. Further and more important, several IDE studies are going on in the US as well as multicentre RCTs in Europe to prove noninferiority to decompression, i.e. the standard treatment. We will see, thereafter, where the place for IPDs will be. So far, one can only state that they are widely used for their ease of implantation mainly, but also for the wrong indication in many instances. This does not discredit the technology, but the user instead. Above that, IPDs are those rare devices that were introduced subsequent to a proof of noninferiority to conservative treatment (i.e. [4-6]). Not many technologies in spine surgery were and are scrutinised in this manner. This holds especially true for nucleus replacement. Not a single good quality report can be found in the literature. It has disastrous results and must be considered absolutely experimental. The only correct attitude to this theoretically attractive concept is a step back to the laboratory (i.e. [7]) and start a carefully designed clinical trial thereafter. 
Now, the main focus was on total disc replacement. As the title of my editorial states, I am convinced that this technology is here to stay, as obviously are the authors. It is also very good to highlight the differences of lumbar and cervical TDR in one article, because this tends to be overlooked.

TDR in general has been through the notorious cycle of all new technologies, in as much as the initial scepticism was followed by a "hype", which is nowadays on its way back to normality.

The good quality studies we have are mainly IDE studies from the US. In essence, they have to be considered class I evidence; however, there are certain known limitations. Foremost is the unblinded nature of the trials, which gives an obvious advantage to the new technology, estimated by EBM specialists to be in the range of $20-30 \%$. This is especially true in a country where new technologies are eagerly awaited by the patients, but the only possibility to have the new device implanted is the participation in a trial.

What these studies provide us with once again is an independent observation with respect to the results of lumbar fusion for symptomatic degenerative disease. They give clear evidence that these results are rather disappointing, which is in striking difference to most surgeons' perception of it, especially with regard to their own results. This alone is a good rationale to look for alternatives, such as TDR or other means of motion preservation. In this respect, the authors' notion that "some debate still exists" regarding fusion is not quite correct. Fusion has been used widely, and its results were not questioned at all for a long time. Only in recent years, this has been the case with the help of several high-class studies. For me, it is obvious that more and more patients will, thus, be no longer treated with traditional ways of fusion. I personally think it already has lost its role as gold standard in many cases or is on the way to do so.

Many sensible people within the community of spinal surgeons have nowadays reached a consensus that a small but stable fraction of their patients, namely around $5 \%$ in the lumbar and $10 \%$ in the cervical region, are good candidates for disc protheses $[8,9]$. This will be the younger and still physically active population and as such per se the minority. The majority of "degenerative spines" will either be candidates for fusion (if you are on the traditionalists' side) or alternative forms of nonfusion techniques.

Cervical TDR will always be easier and more accepted than lumbar for several reasons. The most important one is the fact that you treat a radicular syndrome in the cervical spine instead of an axial pain as in lumbar. This has the advantage that you know exactly where your index level is and that a proper decompression alone will resolve the patient's problem (which by the way practically excludes multilevel TDRs in the cervical spine, because axial pain is not considered an indication for surgery). The protheses are just an add-on that may or may not have a beneficial effect for the patient on the long run. If the hypothetical advantage - the reduction of adjacent level disease-will translate into a clinically meaningful effect is unknown to date and will be very hard to prove, if at all. I would, thus, not use adjacent segment disease as the major argument. But with nothing on the downside except the higher costs, I strongly believe it is justified to use an alternative, which is closer to nature than immediate fusion. In my eyes, TDR is nothing but a slow fusion device. Practically, all prostheses will eventually cease to move sooner or later, which is good, because the rest of the spine will do that, too. TDR is there to decelerate the natural process of degeneration and not to stop it forever. Therefore, I strongly oppose the authors' view that heterotopic ossification and spontaneous fusion is a problem. It is just a very boring argument, reiterated over and over by opponents of the technique. Just ask yourself the question, if for example at the age of 80 , you need one completely mobile segment in your cervical spine with a TDR, implanted 30 years ago, while the rest is stiff as a stick. So, I would advocate a more relaxed view on this. Fusion of these devices is just the natural course. The only important question for the future is to know their average long-term survival. This may be clarified by the cervical TDR registries which are installed in many places, but will take time.

Thus, the other major difference between cervical and lumbar TDR is the fact that the former is about motion preservation if to be successful, while the latter is about motion restoration. Mobilisation of the index segment in lumbar TDR is very important on one hand, but may also promote all the problems related to facet joint degeneration. If mobilisation of the segment is tried in cervical TDR, this negative effect is often very immediate in a considerable subset of patients.

I also concur with the authors that exact positioning of the device in the lumbar spine is very important and deserves a lot of attention. However, I do not agree with the conclusion that the inferior results seen with lumbar TDR are due to technicalities, or the fact that neurosurgeons are less familiar with the anterior, retroperitoneal approach. Most neurosurgeons do not perform lumbar TDR, and the ones that do are as experienced as orthopaedic surgeons with this. Most lumbar prostheses are implanted by experienced spine surgeons. Technicalities, such as positioning, etc. may play a role for unsatisfactory outcome in single cases, but the majority of adverse outcomes are related to indication. Even with the best of efforts and the most accurate diagnostics, there will always remain considerable doubts. The majority of spine surgeons experienced in TDR are, therefore, very firm in their 
position on this. The summary of which is that decision is more important than incision.

All in all, I repeat that, in my opinion, total disc replacement is a technique, which has already found its place in spinal surgery. Only a very limited number of patients are good candidates. These, however, will then profit. Thus, the key issue is to use it wisely and with a conservative attitude regarding indication, especially in the lumbar spine. Low back pain has an extraordinary high incidence in industrialised countries and will, in most instances, not be influenced by surgical measures.

\section{References}

1. Fekete T, Porchet F (2009) Overview of disc arthroplasty-past present and future. Acta Neurochir xxx-xxx

2. Freeman BJ, Davenport J (2006) Total disc replacement in the lumbar spine: a systematic review of the literature. Eur Spine J 15 (Suppl 3):S439-S447

3. Zindrick MR, Tzermiadianos MN, Voronov LI, Lorenz M, Hadjipavlou A (2008) An evidence-based medicine approach in determining factors that may affect outcome in lumbar total disc replacement. Spine 33(11):1262-1269 Review
4. Anderson PA, Tribus CB, Kitchel SH (2006) Treatment of neurogenic claudication by interspinous decompression: application of the X STOP device in patients with lumbar degenerative spondylolisthesis. J Neurosurg Spine 4(6): 463-471

5. Zucherman JF, Hsu KY, Hartjen CA, Mehalic TF, Implicito DA, Martin MJ, Johnson DR 2nd, Skidmore GA, Vessa PP, Dwyer JW, Puccio ST, Cauthen JC, Ozuna RM (2005) A multicenter, prospective, randomized trial evaluating the X STOP interspinous process decompression system for the treatment of neurogenic intermittent claudication: two-year follow-up results. Spine 30 (12):1351-1358

6. Zucherman JF, Hsu KY, Hartjen CA, Mehalic TF, Implicito DA, Martin MJ, Johnson DR 2nd, Skidmore GA, Vessa PP, Dwyer JW, Puccio S, Cauthen JC, Ozuna RM (2004) A prospective randomized multi-center study for the treatment of lumbar spinal stenosis with the X STOP interspinous implant: 1-year results. Eur Spine J 13(1):22-31

7. Hegewald AA, Knecht S, Baumgartner D, Gerber H, Endres M, Kaps C, Stüssi E, Thomé C (2009) Biomechanical testing of a polymer-based biomaterial for the restoration of spinal stability after nucleotomy. J Orthop Surg Res 4:25

8. Auerbach JD, Jones KJ, Fras CI, Balderston JR, Rushton SA, Chin KR (2008) The prevalence of indications and contraindications to cervical total disc replacement. Spine J. 8(5):711-716

9. Fras CI, Auerbach JD (2008) Prevalence of lumbar total disc replacement candidates in a community-based spinal surgery practice. J Spinal Disord Tech 21(2):126-129 